\title{
Thorax computed tomography findings and mortality analysis of a localized outbreak of H1N1 pneumonia in east Part of Turkey in 2013
}

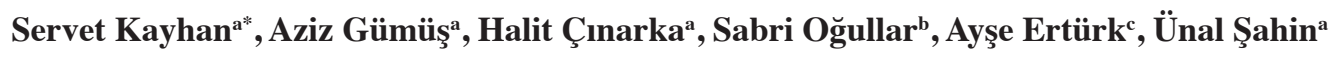 \\ ${ }^{a}$ Department of Chest Disease, Faculty of Medicine, Recep Tayyip Erdoğan University, Rize, Turkey \\ ${ }^{b}$ Department of Radiology, Faculty of Medicine, Recep Tayyip Erdoğan University, Rize, Turkey \\ ${ }^{c}$ Department of Infectious Disease, Faculty of Medicine, Recep Tayyip Erdoğan University, Rize, Turkey
}

\section{ARTICLE INFO ABSTRACT}

\section{Article History}

Received $\quad 10 / 10 / 2013$

Accepted $\quad 20 / 10 / 2013$

\section{* Correspondence to:}

Servet Kayhan

Department of Chest Disease,

Faculty of Medicine,

Recep Tayyip Erdoğan University,

Rize, Turkey

e-mail: kayhanservet@gmail.com
There in we report a local outbreak of H1N1 pneumonia in east part of (Blacksea region) of Turkey. A total of 118 patients admitted to our emergency department with the similar complaints of malaise, high fever, myalgia, cough and dyspnea between December 2012 and April 2013. The diagnosis of H1N1 virus infection was confirmed in 21 hospitalized patients with pneumonia by using real-time polymerase chain reaction method. Five of the 21 patients died due to acute respiratory distress syndrome (ARDS) in a few days. We investigated the radiological manifestations and the risk factors for the mortality of the patients with influenza A (H1N1) virus related pneumonia.

J. Exp.Clin. Med., 2013; 30:339-344

\section{Keywords:}

Computed tomography

H1N1 pandemic

Influenza

Mortality

\section{Introduction}

Influenza A virus is a member of orthomyxovirus family. Antigenic subtyping of influenza A virus is based on 16 subtypes of hemagglutinin and nine subtypes of neuraminidase surface glycoproteins. A global pandemic of a novel influenza A (H1N1) virus (swine origin Influenza A virus) emerged in 2009 and caused nearly 18500 deaths in the world. The antigenic shift of $\mathrm{H} 1 \mathrm{~N} 1$ virus occured in pigs and this novel virus has a quadriple reassortment of one human, one avian and two swine strains (WHO report, 2009).

Unlike seasonal flu, influenza-A H1N1 virus infection causes more complications and mortalities, especially in patients with underlying chronic cardiopulmonary comorbid conditions, immunosuppressive states, pregnancy, diabetes mellitus, obesity and neurological disabilities (Li et al., 2011).

A local outbreak of H1N1 pneumonia emerged in east part of Blacksea region of Turkey in 2013, after four years from the global pandemic. The aim of this study is to investigate the radiological manifestations of Influenza A (H1N1) related pneumonia and the risk factors of the mortality.

\section{Material and methods}

This study was performed in Education and Research Hospital of Recep Tayyip Erdoğan University in Rize (Turkey) between 01 December 2012 and 30 April 2013 and was approved by the Institutional Board of the hospital. The medical records, laboratory and radiological findings of 21 hospitalized patients with $\mathrm{H} 1 \mathrm{~N} 1$ related pneumonia were evaluated retrospectively. We used the recommendations of WHO for $\mathrm{H} 1 \mathrm{~N} 1$ diagnosis and management of disease (WHO report, 2009). Nasopharyngeal swab were taken from suspected cases and the samples were transported to Ankara, Refik Saydam Hygiene Center Virology Laboratory in a viral transport medium and diagnosis of $\mathrm{H} 1 \mathrm{~N} 1$ was confirmed by using real-time polymerase chain reaction (PCR) method. Initial posterior-anterior chest $\mathrm{X}$-ray graphies were obtained in all 
hospitalized patients. Thorax computed tomography (CT) scan was performed in fifteen of twenty-one patients within 24 hour of admission.

\section{Results}

A total of 118 patients were diagnosed as H1N1 influenza A, 37 of the patients were treated with the diagnosis of H1N1 related pneumonia and 21 patients were hospitalized with the diagnosis of severe H1N1 pneumonia in the department of chest disease clinic, five of these patients died due to acute respiratory distress syndrome (ARDS) in intensive care unit (ICU). Nasopharyngeal swabs were taken to identify the virus and to confirm definite diagnosis of $\mathrm{H} 1 \mathrm{~N} 1$ inluenza A virus after the onset of symptoms in suspected cases. The subjects included to study. Were 9 male and 12 female with the mean age of $48 \pm 16,72$ years ranging from 24 to 82 years. Thorax CT scans were performed in 15 of 21 patients with H1N1 pneumonia within 24 hour of admission. One of the patients was pregnant and the other five patients with a relatively good clinical table did not undergo a CT scan examination. General characteristics, risk factors and radiological findings of these fifteen patients were shown in Table 1. The CT findings had similarities with each other and consisted of bilateral irregular pneumonic infiltrations or air bronchograms, alveolar consolidations and ground glass appearance with or without minimal pleural effusions (Figure 1-15). The management of disease was provided according to WHO recommendations as shown in clinical triage algorithms in Table 2 (WHO report, 2009). We used the antiviral drugs (oseltamivir or zanamivir), antimicrobial therapy with broad spectrum antibiotics for possible bacterial coinfections and respiratory supportive treatments including maintaining an adequate fluid and electrolyte balance, supplemental oxygen therapy and non-invasive mechanical ventilation if needed in all twenty-one cases. Five of these cases died due to acute respiratory distress syndrome (ARDS). On the other hand in one of the female patients having a risk factor of pregnancy, H1N1 pneumonia was detected after a mild respiratory symptoms and she recovered completely after inhalational zanamivir treatment.

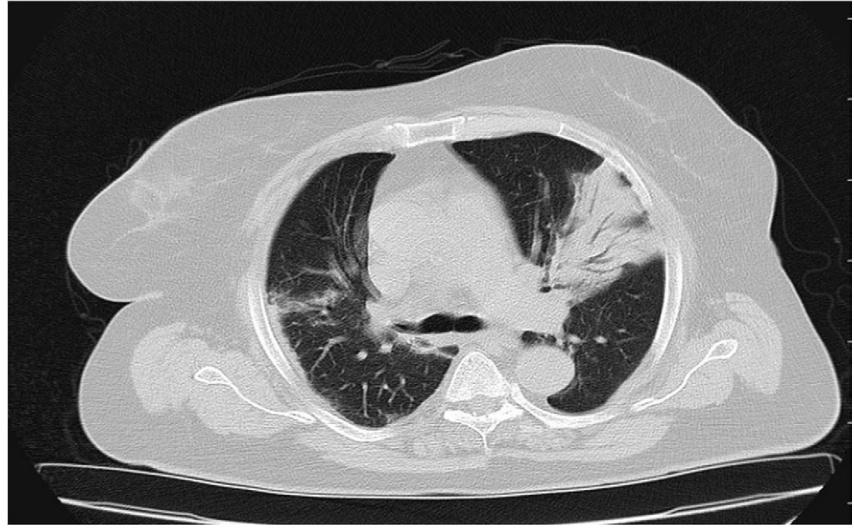

Fig. 1. Thorax CT image (parenchymal window) of patient-1 shows consolidation and air-bronchogram in anterior segment of left upper lobe, ground glass appearence in anterior segment of right upper lobe and pleural thichenning in this area.

Another patient with asthma and severe pneumonia who admitted $8^{\text {th }}$ day of symptoms also recovered with oseltamivir treatment and without ICU support (Figure 2). These five cases (Figure 4, 6, 8, 12 and 13) with respiratory failure were supported by mechanical ventilation in respiratory intensive care unit and the treatment of extracorporal membrane oxygenation (ECMO) could be performed to only one of these cases, but five patients with severe pneumonia and ARDS did not respond to any treatment modalities. We observed that the late admission to hospital was the main risk factor in all five cases and the comorbidities including obesity in three female patients, diabetes mellitus and mental retardation were the additional risk factors for the mortality in four patients. In this study, we observed that invasive mechanical ventilation even ECMO treatment did not change the mortality rate of H1N1 related pneumonia if complicated with ARDS. As a result of the study the mortality rates were found as $4.23 \%$ (5 in 118) in all influenza A (H1N1) cases, $13.51 \%$ (5 in 37) in cases complicated with $\mathrm{H} 1 \mathrm{~N} 1$ pneumonia, $23.8 \%$ (5 in 21$)$ in hospitalized cases due to $\mathrm{H} 1 \mathrm{~N} 1$ pneumonia and $100 \%$ (5 in 5 ) in cases with H1N1 pneumonia complicated with ARDS.

Table 1. General characteristics, risk factors, main radiological findinds in CT, treatment strategies and the survivals of the patients with H1N1 related pneumonia are summarized

\begin{tabular}{|c|c|c|c|c|c|c|}
\hline No & Age & Gender & Risk factor & Main radiological findings & Treatment & Survivals \\
\hline 1 & 82 & $\mathrm{~F}$ & age ( $>65$ year $)$ & ground glass appearence, air-bronchogram & NIMV, MT in CDC & survived \\
\hline 2 & 51 & $\mathrm{~F}$ & asthma, obesity, late admission & tree-in bud appearence & NIMV, MT in CDC & survived \\
\hline 3 & 24 & M & - & ground glass appearence & MT in CDC & survived \\
\hline 4 & 54 & M & late admission & ground glass appearence & $\mathrm{MV}, \mathrm{ECMO}$ in ICU & died \\
\hline 5 & 48 & $\mathrm{~F}$ & - & ground glass appearence & MT in CDC & survived \\
\hline 6 & 29 & $\mathrm{~F}$ & obesity, late admission & ground glass appearence & $\mathrm{MT}, \mathrm{MV}$ in ICU & died \\
\hline 7 & 26 & $\mathrm{~F}$ & - & tree-in bud appearence & MT in CDC & survived \\
\hline 8 & 42 & $\mathrm{~F}$ & obesity, late admission & consolidations, ground glass appearence & MT, MV in ICU & died \\
\hline 9 & 59 & M & late admission & ground glass appearence & MT in CDC & survived \\
\hline 10 & 44 & M & - & air-bronchogram, pleural effusion & MT in CDC & survived \\
\hline 11 & 38 & $\mathrm{~F}$ & - & air-bronchogram & MT in CDC & survived \\
\hline 12 & 67 & $\mathrm{~F}$ & DM, COPD, age ( $>65$ year), late admission & ground glass appearence & $\mathrm{MT}, \mathrm{MV}$ in ICU & died \\
\hline 13 & 34 & M & mental retardation, late admission & ground glass appearence & MT, MV in ICU & died \\
\hline 14 & 53 & $\mathrm{~F}$ & - & ground glass appearence, interstitial thickenning & MT in CDC & survived \\
\hline 15 & 69 & M & age ( $>65$ year) & ground glass appearence & MT in CDC & survived \\
\hline
\end{tabular}

F: female, M: male, obesity: body mass index $>30 \mathrm{~kg} / \mathrm{m}^{2}$, late admission: the patient who admitted to hospital after 7 days (or longer) from the onset of symptoms, MT: medical treatments, CDC: chest disease clinic, ICU: intensive care unit, MV: mechanical ventilation, NIMV: non-invasive mechanical ventilation, ECMO: extracorporal membrane oxygenation 


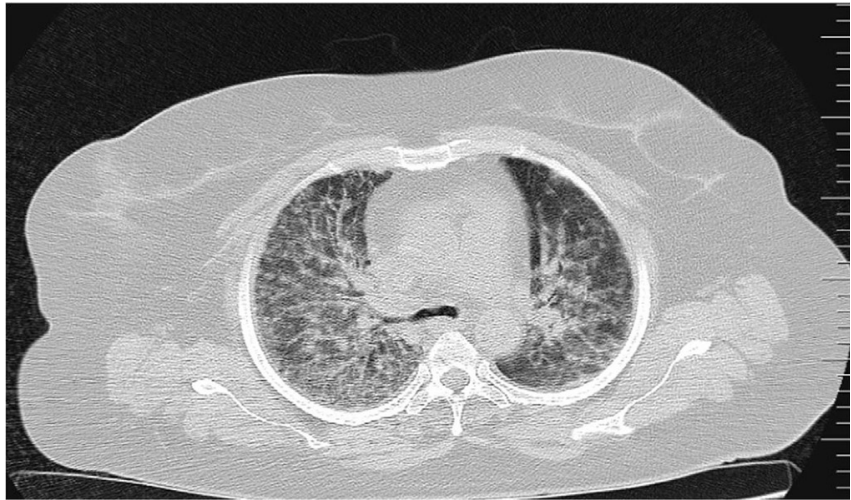

Fig. 2. Thorax CT image (parenchymal window) of patient-2 shows bilateral multifocal acinary nodules and tree-in bud appearence.

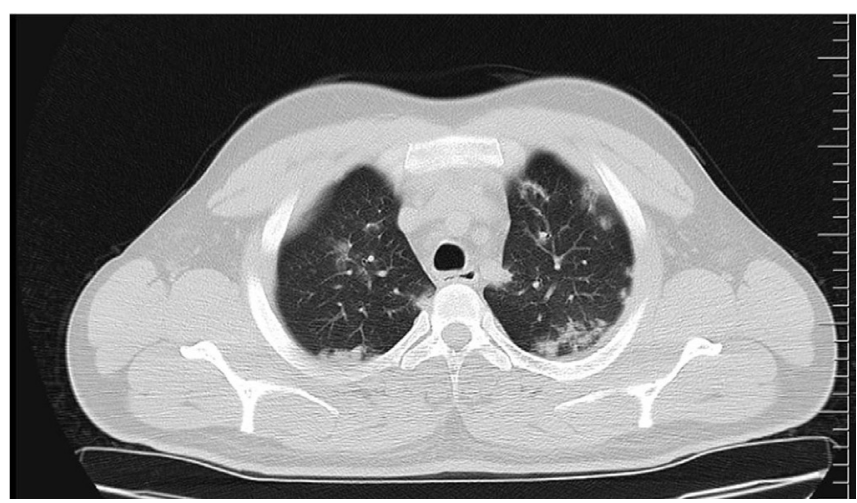

Fig. 3. Thorax CT image (parenchymal window) of patient- 3 reveals bilateral focal acinary nodules and ground glass appearence in peripheral regions.

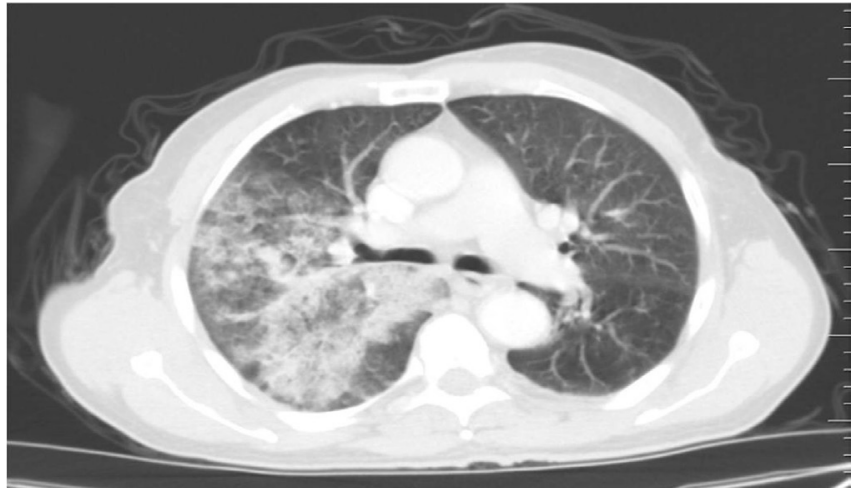

Fig. 4. Thorax CT image (parenchymal window) of patient-4 shows diffuse acinary infiltration and ground glass appearence in anterior segment of right upper lobe and superior segment of right lower lobe.

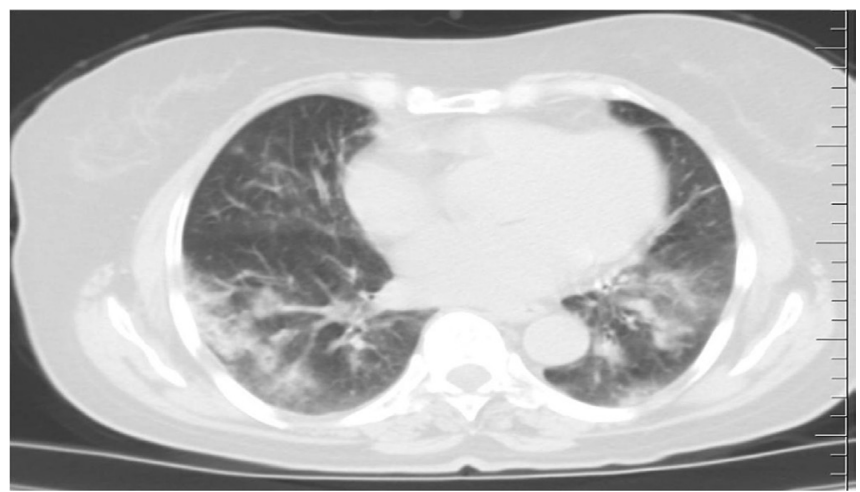

Fig. 5. Thorax CT image (parenchymal window) of patient-5 shows bilateral acinary infiltrations and ground glass appearence in superor segments of lower lobes.

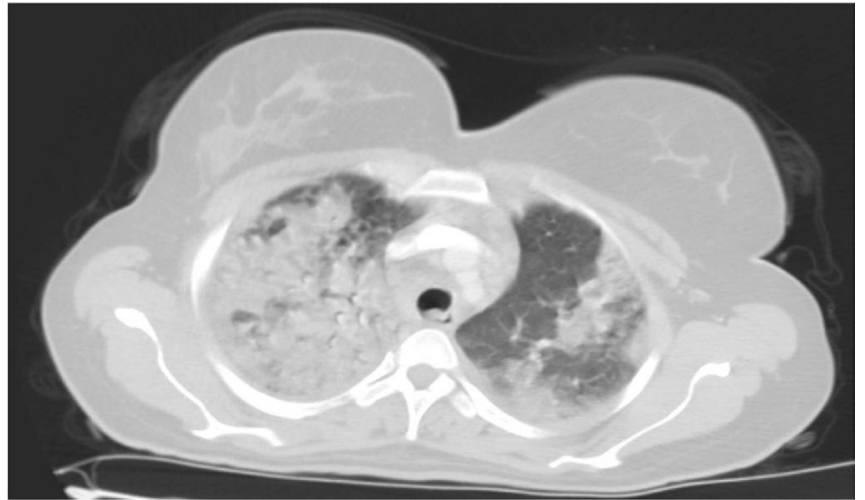

Fig. 6. Thorax CT image (parenchymal window) of patient-6 shows bilateral, diffuse acinary images and ground glass appearence.

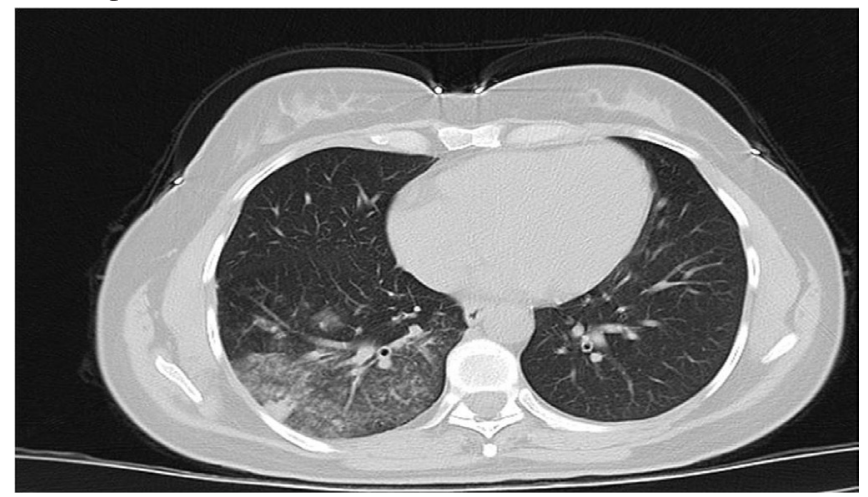

Fig. 7. Thorax CT image (parenchymal window) of patient-7 shows nodulary consolidation in subpleural region with peripheral ground glass appearence and tree-in bud appearence in superior segment of right inferior lobe.

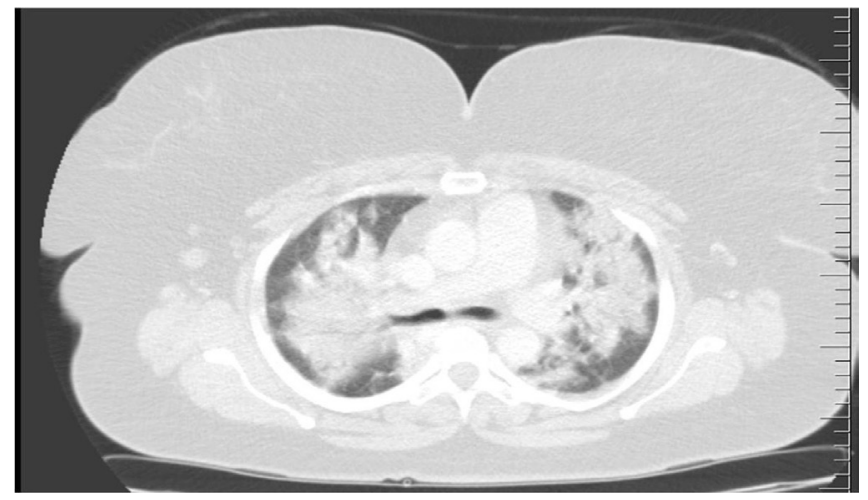

Fig. 8. Thorax CT image (parenchymal window) of patient- 8 shows bilateral diffuse consolidation ground glass appearence and pneumonic infiltration.

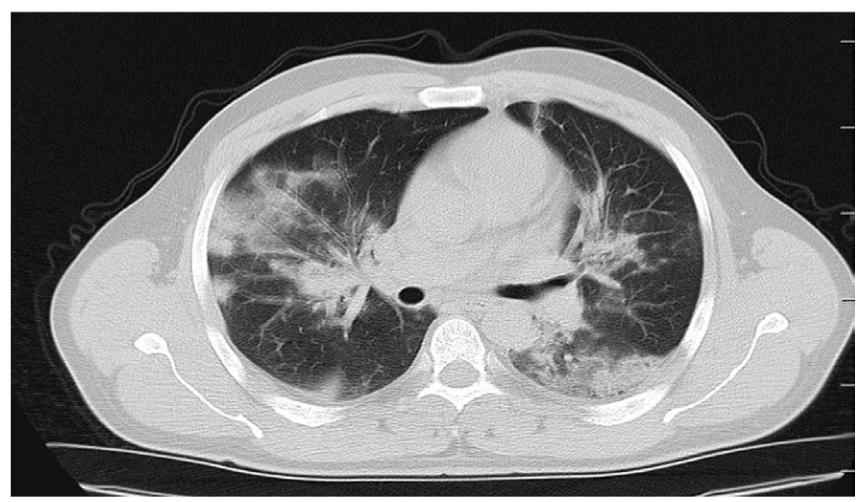

Fig. 9. Thorax CT image (parenchymal window) of patient-9 shows bilateral ground glass appearence and consolidations, air bronchograms in anterior segment of right upper lobe. 


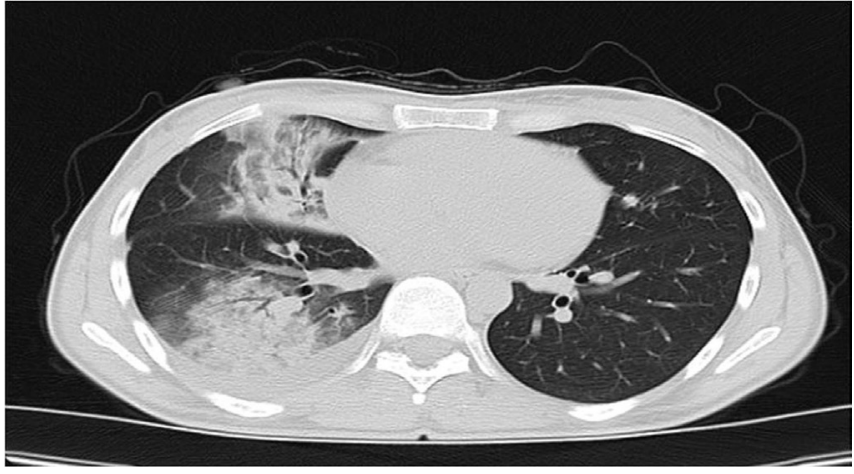

Fig. 10. Thorax CT image (parenchymal window) of patient-10 shows ground glass appearence and air-bronchograms in anterior segment of right upper lobe and superior segment of right lower lobe, pleural effusion in right hemithorax.

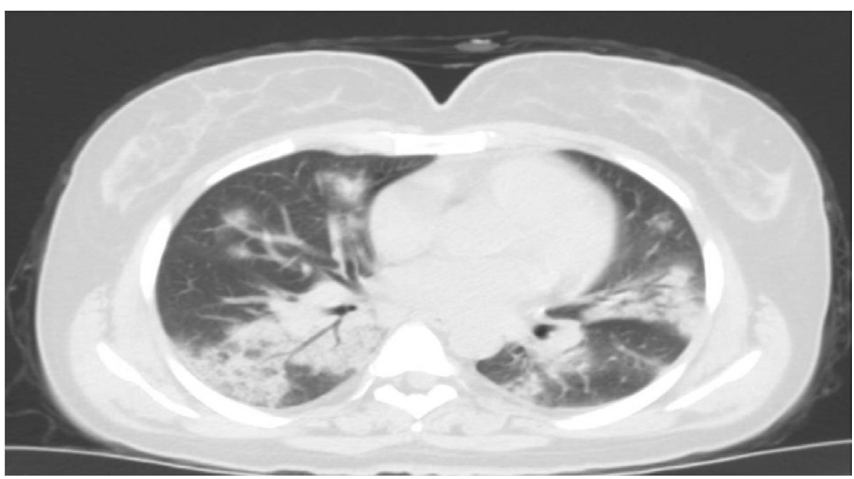

Fig. 11. Thorax CT image (parenchymal window) of patient-11 shows bilateral air-bronchograms and consolidations in superior segments of lower lobes and anterior segments of upper lobes.

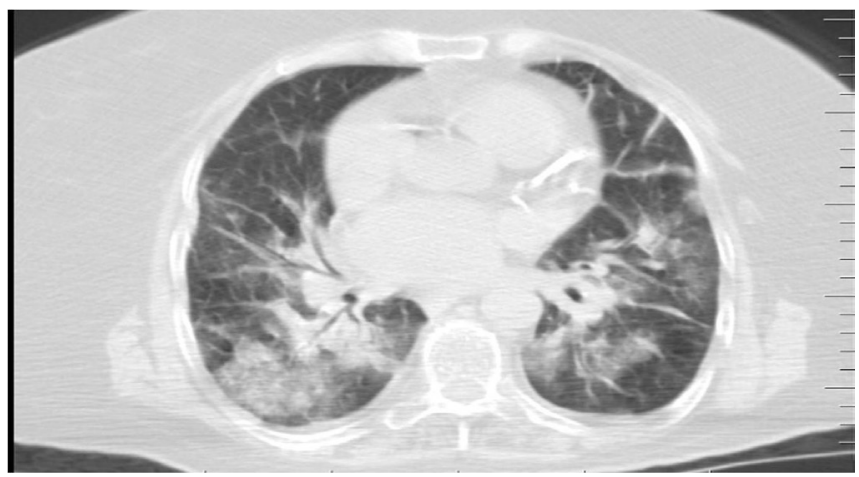

Fig. 12. Thorax CT image (parenchymal window) of patient-12 shows bilateral ground glass appearence, segmentary consolidations and air-bronchograms in superior segments of lower lobes.

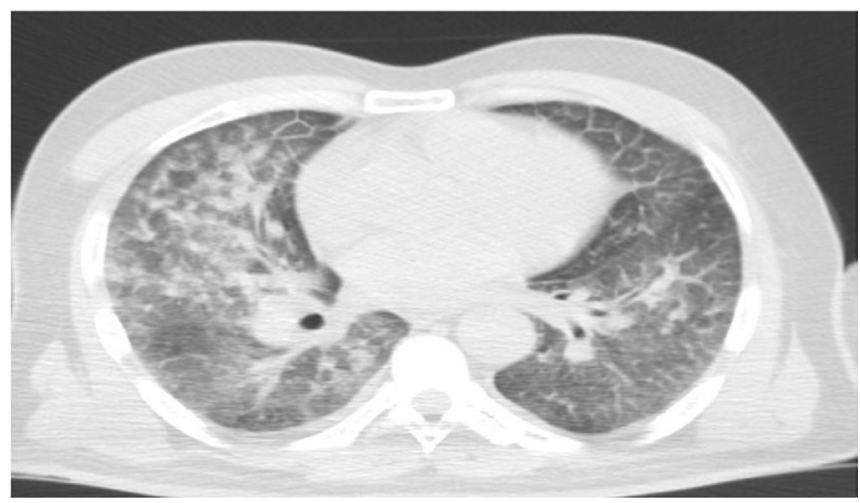

Fig. 13. Thorax CT image (parenchymal window) of patient-13 shows multifocal nodulary infiltrations and peripheral ground appearence in right upper lobe.

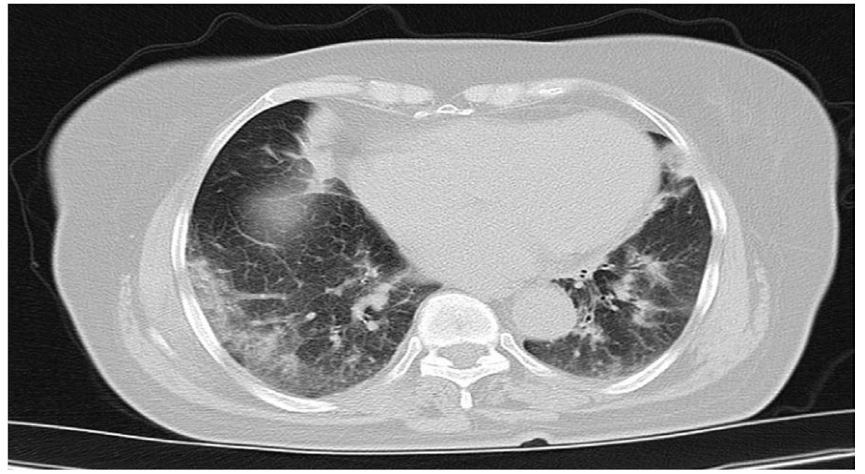

Fig. 14. Thorax CT image (parenchymal window) of patient-14 shows bilateral ground glass appearence and interstitial thickenning in lower lobes.

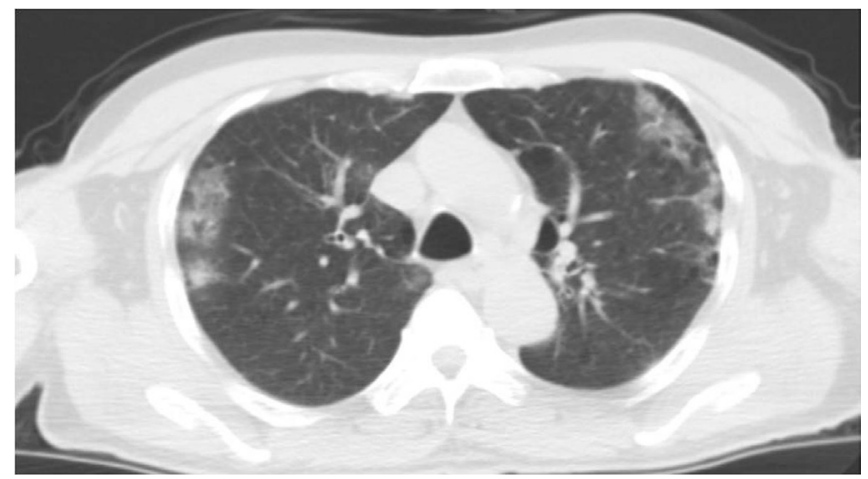

Fig. 15. Thorax CT image (parenchymal window) of patient-15 shows bilateral, multifocal and subpleural ground glass appearence in upper lobes.

\section{Discussion}

Community acquired pneumonia is a major cause of deaths from infectious diseases especially in developed countries. Respiratory viruses, most frequently influenza A and B, adenovirus, and respiratory syncytial virus, account for $10-40 \%$ of all community-acquired pneumonia (Marcos et al., 2009). The mortality rate of community acquired pneumonia varies and is less than $1 \%$ in outpatient departments where it can exceed up to $50 \%$ in patients admitted to ICU (Woodhead et al., 2006; Akram et al., 2011). Influenza pandemics occur as a result of antigenic shift in the surface glycoproteins (hemagglutinin and neuraminidase) of the virus. Primary pandemic influenza A H1N1 pneumonia has been emerged in 2009 with a high mortality rate. Autopsy reports of the patients with H1N1 pneumonia showed severe hemorrhagic pneumonitis, interstitial inflammation and diffuse alveolar damages (Capelozzi et al., 2010). In this local outbreak viral pneumonia, the major cause of mortality was ARDS and we found the mortality rate of influenza $\mathrm{A}(\mathrm{H} 1 \mathrm{~N} 1)$ as $4.23 \%$ in outpatient department, $23.8 \%$ in hospitalized cases with pneumonia and $100 \%$ in cases complicated with peumonia and ARDS and admitted to ICU.

Classical symptoms of influenza are sudden onset of headache, fever, cough, pharyngeal irritation, myalgias are malaise. Respiratory symptoms such as dyspnea and chest tightness, gastrointestinal symptoms such as vomiting and diarrhea, have been frequently reported during influenza A H1N1 pandemics in 2009 (Riquelme et al. 2011). In this study we observed the symptoms of classical seasonal influenza mainly high fever $\left(\geq 38{ }^{\circ} \mathrm{C}\right)$, non productive cough, dyspnea and our patients did not suffer from gastrointestinal system. 


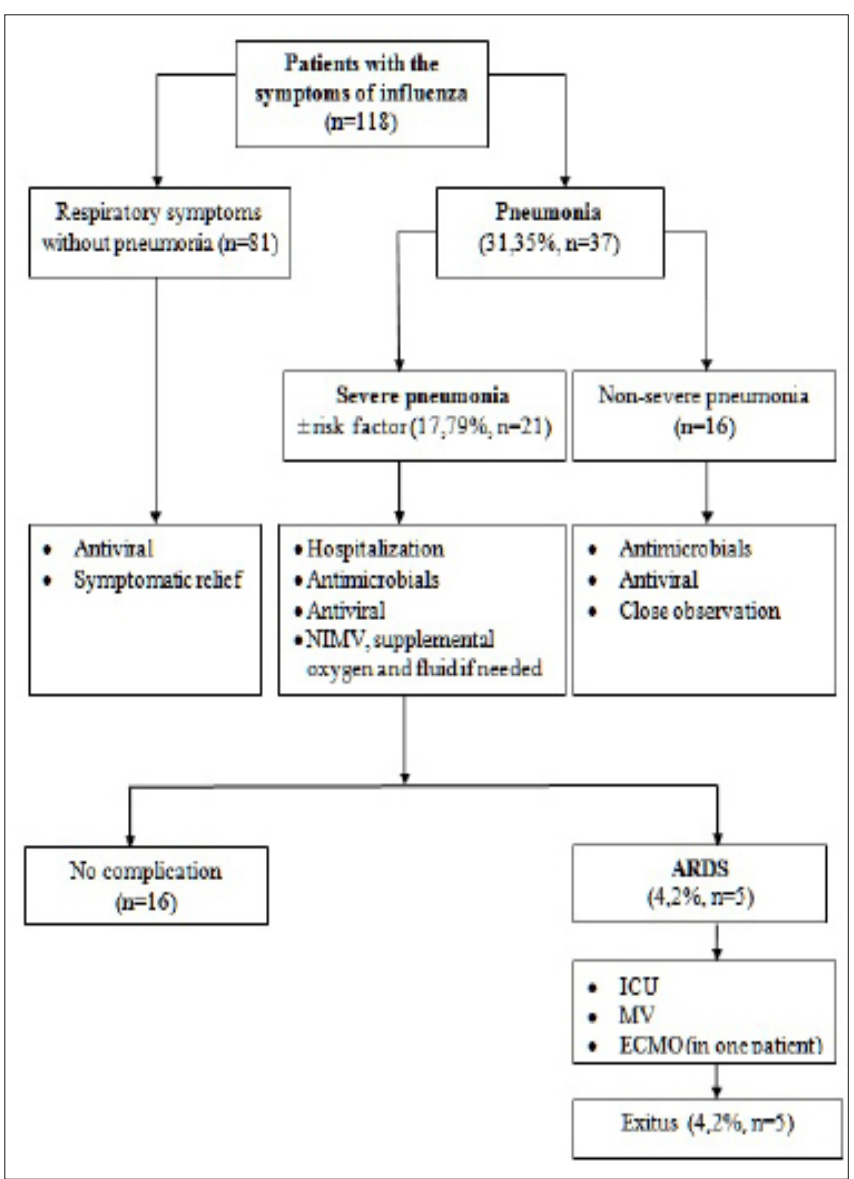

Table 2. Clinical triage algorithms for management of the patients with influenza A (H1N1). A total of 118 patients were admitted with the sypmtoms high fever and respiratory syptoms, 37 of them were diagnosed with pneumonia, 21 patients were hospitalized and authonticated with the diagnosis of H1N1 pneumonia, five of the cases $(4,2 \%)$ complicated with ARDS and did not respond any treatment.

NIMV: Noninvasive mechanical ventilation, ARDS: Acute respiratory distress syndrome, ICU: intensive care unit, MV: mechanical ventilation, ECMO: extracorporal membrane oxygenation

Complications of influenza A (H1N1) infection are viral pneumonia, bacterial coinfections, alveolar hemorrhage, acute respiratory failure, ARDS and multiple organ failure. Pneumonia and ARDS account for the majority of complications and mortality that accompany pandemic influenza infection (Viasus et al., 2011). Our results in the present study also supported the finding of previous studies.

According to previous studies, some of the patients with underlying pulmonary and cardiac comorbid conditions, immunosuppressive states, pregnancy, diabetes mellitus, obesity, prior neurological disabilities, children and young adults were found to be at high risk for development of severe H1N1 disease (Li et al., 2011). In this study, we also observed that the patients with the comorbidities including obesity, asthma, diabetes mellitus, neuropsychiatric disability and pregnancy have high risk for development of severe H1N1 infection. Primary viral pneumonia and ARDS were the major complications of our patients.

An early diagnosis and consequently abrupt onset of antiviral treatment and ventilatory support with supplemental oxygenation and non-invasive mechanical ventilation reduces the mortality of patients with severe H1N1 pneumonia (Rello et al., 2009). As using recommended strategies, we managed to recover sixteen $(76.19 \%)$ of hospitalized patients with severe $\mathrm{H} 1 \mathrm{~N} 1$ peumonia and $95.8 \%$ of all $\mathrm{H} 1 \mathrm{~N} 1$ cases.

The radiological appearance of H1N1 pneumonia can not be easily distinguished from pulmonary edema and interstitial lung disease on chest $\mathrm{x}$-ray. Pleural effusions may also be present. Computed tomography scans or high resolution CT can add further diagnostic insight and may be useful to differentiate primary viral pneumonia from the other interstitial pathologies. Bilateral, multifocal consolidations associated with ground-glass opacities are the predominant findings of influenza A H1N1 pneumonia and are often associated with a more severe clinical course (Shaham et al., 2011; Perez-Padilla et al., 2009). All we know that first diagnostic method for detecting the lung pathologies is chest x-ray and we obtained chest $\mathrm{x}$-rays for all patients. We used CT in fifteen of our patients for providing a better radiological evaluation for the patients with severe clinical illness and we observed that ground-glass appearence was the major radiological finding and associated with severe clinical course in eleven (73.3\%) of the patients with H1N1 pnemonia and in all of the five patients complicated with ARDS. The most frequent findings on high resolution CT were the thickening of the peribronchovascular space, intralobular and subpleural septal thickening, bronchiectasis, mosaic image of perfusion, pulmonary condensation zones, fibrotic and atelectasic bands. These findings are not specific for $\mathrm{H} 1 \mathrm{~N} 1$ infections and can be exist in any interstitial lung diseases, but the clinical and radiological correlations may help to physicians in diagnosing the disease especially during an outbreak of respiratory viruses. The other radiologic manifestations of $\mathrm{H} 1 \mathrm{~N} 1$ infection are pneumothorax, pneumomediastinum, atelectasis, pleural fluids, lymphadenopaties, cavitation and necrosis. These findings are very rare and related to disease severity and complications (Perez-Padilla et al., 2009; Shaham et al., 2011). The patients presented with the clinical findings of influenza should be carefully followed-up by radiological graphies in terms of rapid progression of disease.

\section{Conclusions}

Ground-glass appearence and irregular alveolar consolidations are the predominant $\mathrm{CT}$ findings of H1N1 related pneumonia. To reduce the mortality, an earlier diagnosis and rapid onset to antiviral (oseltamivir or zanamivir) treatment should be the main strategy in the management of $\mathrm{H} 1 \mathrm{~N} 1$ related pneumonia during an outbreak.

\section{REFERENCES}

Akram, A.R., Chalmers, J.D., Hill, A.T., 2011. Predicting mortality with severity assessment tools in out-patients with community-acquired pneumonia. Q.J.M. 104, 871-879.

Capelozzi, V.L., Parra, E.R., Ximenes, M., Bammann, R.H., Barbas, C.S., Duarte, M.I., 2010. Pathological and ultrastructural analysis of surgical lung biopsies in patients with swine-origin influenza type A/H1N1 and acute respiratory failure. Clinics (Sao Paulo). 65, $1229-1237$.

Li, M., Zhu, J.B., Chen, G.Q., Yang, W.Y., Tao, C., Wang, X.H., 2011. Influenza A (H1N1) pneumonia: An analysis of 63 cases by chest CT. 
Chin. Med. J. 124, 2669-2673.

Marcos M.A., Esperatti, M., Torres, A. 2009. Viral pneumonia. Curr. Opin. Infect. Dis. 22, 143-147.

Perez-Padilla, R., de la Rosa-Zamboni, D., Ponce de Leon, S., Hernandez, M., Quinones-Falconi, F., Bautista, E., Ramirez-Venegas, A., RojasSerrano, J., Ormsby, C.E., Corrales, A., Higuera, A., Mondragon, E., Cordova-Villalobos, J.A., INER Working Group on Influenza et al. 2009. Pneumonia and respiratory failure from swine-origin influenza A (H1N1) in Mexico. N. Engl. J. Med. 361, 680-689.

Rello, J., Rodriguez, A., Ibanez, P., Socias, L., Cebrian, J., Marques, A., Guerrero, J., Ruiz-Santana, S., Marquez, E., Nogal-Saez, F.D., AlvarezLerma, F., Martínez, S., Ferrer, M., Avellanas, M., Granada, R., Maraví-Poma, E., Albert, P., Sierra, R., Vidaur, L., Ortiz, P., Prieto del Portillo, I., Galván, B., León-Gil, C. H1N1 SEMICYUC Working Group: Intensive care adult patients with severe respiratory failure caused by Influenza A (H1N1)v in Spain. Crit. Care. 13, 148.

Riquelme, R., Torres, A., Rioseco, M.L., Ewig, S., Cilloniz, C., Riquelme, M., Inzunza, C., Polverino, E., Gomez, Y., Marcos, M.A., Contreras, C., Gabarrus, A., Fasce, R., 2011. Influenza pneumonia: A comparison between seasonal influenza virus and the H1N1 pandemic. Eur. Respir. J. 38, 106-111.

Shaham, D., Bogot, N.R., Aviram, G., Guralnik, L., Lieberman, S., Copel, L., Sosna, J., Moses, A.E., Grotto, I., Engelhard, D., 2011. Severe influenza A (H1N1): the course of imaging findings. Isr. Med. Assoc. J. 13, 591-596.

Viasus, D., Pano-Pardo, J.R., Pachon, J., Campins, A., Lopez-Medrano, F., Villoslada, A., Farinas, M.C., Moreno, A., Rodriguez-Bano, J., Oteo, J.A., Martinez-Montauti, J., Torre-Cisneros, J., Segura, F., Gudiol, F., Carratala, J., Novel Influenza A (H1N1) Study Group of the Spanish Network for Research in Infectious Diseases (REIPI), 2011. Factors associated with severe disease in hospitalized adults with pandemic (H1N1) 2009 in Spain. Clin. Microbiol. Infect. 17, 738.

Woodhead, M., Welch, C.A., Harrison, D.A., Bellingan, G., Ayres, J.G. 2006. Community-acquired pneumonia on the intensive care unit: secondary analysis of 17,869 cases in the ICNARC Case Mix Programme Database. Crit. Care. 10, 1.

World Health Organization. 2009. Outbreak of swine origin influenza A (H1N1) virus infection-Mexico, March-April 2009. http//www.who.int, MMWR Morb Mortal Wkly Rep. 58, 467. September 2011. 